\title{
A Review of Contemporary Challenges in Business Culture
}

\author{
Marcel Biewendt \\ mbiewendt@yahoo.de \\ Szent István University - Kaposvár Campus \\ Florian Blaschke \\ f.d.blaschke@gmail.com \\ Szent István University - Kaposvár Campus \\ Arno Böhnert \\ arno.boehnert@gmail.com \\ Szent István University - Kaposvár Campus \\ https://doi.org/10.51137/ijarbm.2021.2.1.1
}

\begin{abstract}
The following article deals with the basic principles of intercultural management and possible improvements in terms of cultural, ethnic and gender diversification. The results are exemplarily applied to a bank located in Germany. The aim of this paper is to find out to what extent intercultural management could improve the productivity of Relatos-Bank in dealing with foreign employees or employees with a different cultural background. To achieve this goal, the authors conduct a literature research. The main sources of information are books, journal articles and internet sources. It becomes clear that especially the different perceptions of different generations have a potential for conflict, which can be counteracted by applying presented scientific models. Equalizing the salaries of female and male employees and equalizing the rights and distribution of power could also be the key to becoming an open-minded, dynamic and fair organization that is prepared for the rapidly changing environment in which it operates.
\end{abstract}

Keywords - Diversity, Business Culture, Future Challenges, Contemporary

\section{Introduction}

The emergence of new technologies, a new self-image in dealing with foreign cultures, the need to adapt processes and key figures to international standards and global supply chains is gaining more and more importance for global and multinational operating enterprises. In order to visualize potential problems of this adaptation process, the fictional Relato Bank, which operates on the European as well as on the US American market, is used for this paper. The structures of the German Relatos-Bank made it necessary to reflect on and evaluate the way in which human resources management is carried out within the Relato Bank itself. True to the company motto "capable before the competition", this paper is intended to enable managers to identify future challenges on the basis of scientific findings and to give advice on how to meet them correctly. Management will also benefit from the ability to 
identify how existing weaknesses can be transformed into future strengths and new ways to create synergies.

Since Germany has been a homogeneous society for decades and is only just beginning to experience the challenges, benefits and risks of an increasingly heterogeneous society in business life, the process of changing habits is potentially more drastic and strenuous than in the USA, for example, which was long a melting pot of cultures (Fraenkel, 2011). Furthermore, the largest market for Relatos financial products is the USA, which often has a slightly to completely different approach to different business habits (MüllerElmau, 1997). This paper provides a professional and scientific approach to management and adaptation to this change.

\section{Literature Review}

Several authors developed theories and dealt with research on culture, cultural diversification and its management. In order to ensure a scientifically sound background, this chapter offers a selection of important and relevant literature on intercultural management.

To understand how different cultures influence each other, it is first necessary to define what culture is, or at least to bring them closer together. Basic patterns of culture are both visible and invisible characteristics, social orders and attitudes (Kroeber, 1938). Nevertheless, time influences the public image of culture, so it is interesting to find out how culture is seen today. The most common theoretical approaches and studies on this topic are presented below.

\subsection{An Early Disposition of CCM by Kroeber and Kluckhohn}

In 1952, shortly after the end of the Second World War, the authors Kroeber and Kluckhohn wrote basic literature on intercultural management (Edel et al., 1954). They collected several definitions and concepts of what culture is. The oldest quotation refers to Tylor in 1871 which described that culture or civilization is the complex whole comprising knowledge, faith, art, law, morals, habits and all the other skills and attitudes that man has acquired as a member of society. As the world has become smaller (through the use of technology) and feels like a different place since then, it is worth comparing this statement with a definition of today (Schneider et al., 2014). Exemplary the Oxford Dictionary provides the definition that culture is the collective contemplation of the arts and other manifestations of human intellectual achievement (Oxford-Dictionaries, 2021).

A closer look reveals that the first explanation refers to an individual member of a society, while the second quote defines culture more or less as the achievements of a global collective. This may reflect the contemporary philosophy of life of the respective author, since in 1871 society was defined in a global aspect much more than the state in which one lives (national culture), and not as humanity (Elizabeth Ten Dyke, 2006). 


\subsection{The Iceberg Model Explained}

A good instrument for visualizing the often-unexpected number of cultural factors is the iceberg model. As the name suggests, cultural features have parts that are directly visible (above water) and a much larger quantity that is invisible to untrained people (under water) (Hines, 2010).

Recognizable for untrained people:

- Behavior (e.g. to a certain aspect body language)

- Apparel and fashion

- Oral communication style

- $\quad$ Characteristics

Unrecognizable for untrained people:

- How people perceive the world

- Political values

- Sexual orientation

- Violence tendency

- Skills (Soft- and hard skills)

- Sensibility

\subsection{The Psychology of Culture Shock by Colleen Ward}

Especially in larger companies or consultancies, it is common to send employees abroad to work in offices located all over the world (Vandermerwe \& Chadwick, 1989).

Therefore, companies need to provide management with tools to realize their performance at the same level as in their country of origin. When living in a foreign country for a long period of time, there is pressure, perhaps initially unobserved, to adapt to the manners of that country, including behavior, communication and lifestyle and food (Zhou et al., 2008). Since the employee has to stay in this foreign environment and has no chance of escaping, this often leads to so-called culture shock. In a country where the differences to the home country are so great or contradictory, employees can feel overwhelmed and uncomfortable, which leads to a performance deficit (culture shock) (Ward et al., 2015).

Of course, all this also applies, especially in the context of globalization, to today's immigration situation, as refugees and immigrants are often confronted with different religions, legal systems and customs.

\subsection{Cultural Dimensions by Geert Hofstede}

Another important system for implementing and measuring cultural management is Geert Hofstede's concept of the cultural dimension of nations.

The scientist Hofstede developed a concept that describes cultural characteristics in addition to six dimensions. With these six dimensions it is possible to quantify these particularities and compare them with other countries. Key figures of Hofstede are (Geert Hofstede): 
- Power Distance index

- Individualism vs. collectivism

- Uncertainty avoidance index

- Masculinity vs. femininity

- Long term orientation vs. short term orientation

- Indulgence vs. restraint

With these instruments, Relatos Bank will be able to provide detailed statistics and key figures on how best to trade in a given country. After applying the Hofstede model (Hofstede, 2001), Relatos will be able to decide how to:

- Negotiate with foreign business partners

- Prepare employees for business trips

- Handle foreign (and new) employees in Germany

- Develop marketing strategies

- Design products

- Present the company's appearance

Conflict potential can be those effectively turned into synergy as the respective department of Relatos can develop a plan, based on the employee's/ country's values and habits, at an early stage and is aware of the differences.

\subsection{A Formal Theory of Social Power by French, Jr.}

In "A formal theory of social power", French Jr. deals with "effects of the power structure of the group, the effects of communication patterns, the effects of patterns of opinion, and leadership" (French, 1956). This system is beneficial to analyze deeper of how individuals at Relatos interact with each other or should interact with each other to increase productivity while considering their amount and style of power given by different circumstances. French is categorizing where each individual's power derives from:

- Personal Power

Derives from reciprocally feelings; association

- Expert Power

Derives from expertise in a certain field of work or research

- Position Power

Derives from the system that both individuals subordinate themselves

- Reward Power

Derives from the ability to reward individuals for being e.g. pally. Presupposes material or immaterial resources to re-ward others.

- Coercive

Derives from the ability to punish individuals for not acting as wished. Presupposes material or immaterial resources to punish others.

- Information 
Derives from the actual and factual knowledge that others cannot have or must not have.

At Relatos, all of the given points are present. Some of them are more preferable than others e.g. Reward vs. Coercive Power. Rewards or in psychology terms positive reinforcement will create a beneficial effect which lasts longer than short-term effective punishment (Maag, 2001). In general, man-agers and empowered employees at Relatos should prefer to gather power by expertise, as it will benefit both the company by increasing competitive-ness and the employees by giving them a legitimate reason to believe in the given power.

\section{Use Case: Relatos - Elaboration of Further Implications}

The paper assumes that the Relatos Bank has faced an increase of applications of professionals from all over the world as Germany proved to be a financially sustainable country during the financial crisis of 2008 and is still one of the most potent economies worldwide (Reisenbichler \& Morgan, 2012). Relatos wants to use the full potential of every possible applicant for the German headquarter. It shall not matter of which country he or she comes from. Relatos as well wants to expand further in its key market USA. Therefore, it is crucial to set up an action plan of how to manage possible cultural conflicts that could occur within both Germany and the US.

When discussing Cross Cultural Management several systems and theories need to be considered, as shown by the literature review. A few selected theories will help to support foreign applicants in Germany (inbound) and others will serve to enhance success in foreign markets (outbound).

\subsection{Inbound}

- Iceberg Model

- Culture Shock

Every year around 30 employees from abroad are sent to Frankfurt to support the local team in certain projects. These projects last between 3 and 6 months whereas the foreign employees have to acclimatize them-selves fast in order to work on a high productive level. The majority of guest employees come from the US. Even due to the fact the US is a western country, there are different believes in how the world and business works (Chen \& Bouvain, 2009). This may lead to misunderstanding, blockade attitude, a lack of effective and efficient project processes, a gap of harmony within the team and ultimately the termination of the project because of violating deadlines or expenditure limits. Examples of, maybe unknown or unexpected, cultural/ business behavior differences between Germany and the US are (Ferner \& Quintanilla, 1998): 
- Punctuality

- Small-Talk during work

- Time frame of making decisions

- Thoroughness

- Change Management

- Style of communication (direct vs. indirect)

In addition, the overall circumstances, the food, the habit of the colleagues, the approach of how to interact with supervisors will most likely lead to the so-called cultural shock to guests. However, mitigating this effect is possible with the right preparation and the knowledge what a culture shock is.

\subsection{Outbound}

- Six Dimensions of Hofstede

- Culture Shock

- A formal theory of social power

In exchange with the 30 incoming employees, every year Relatos is sending 30 of the local employees to various locations around the world. Almost $70 \%$ (21) of them are sent to Los Angeles, Palo Alto and San Francisco in California, USA. In particular, the business development managers have the task of opening up new fields of activity, concluding contracts and acquiring new customers (Keil et al., 2008). To be successful it is crucial to prepare them in advance and teach them which differences could occur during their negotiations abroad. In addition, it is necessary to give them insights of how cultural habits differ from ours to prevent culture shocks as well. The biggest factors of conflict potential, related to the theory of cultural dimension by Geert Hofstede, are the uncertainty avoidance (Ger.: 65/100; U.S.: 46/100), the long-term orientation (Ger.: 83/100; U.S.: 26/100) and the way of indulgence/ restraint (Ger.: 40/100; U.S.: 68/100) (Geert Hofstede).

\subsection{Evaluation of CCM Methods within the Relatos Bank}

Unlike other multinational enterprises, the Relatos Bank has almost no cultural diversification within its German headquarter. On the one hand, incoming foreign employees as well as local employees, who are sent abroad, are not affected by any preparation, guidelines or supervising. On the other hand, each year the number of foreign employees, co-workers, contractors and supervisors is increasing. The interactions between local and foreign workers are often interrupted by unnecessary conflicts. Not dealt with correctly they turn out to be destructive instead of creating productive opportunities.

Before discussing further solutions to prevent conflicts, elaborating of how to manage existing conflicts within the Relatos Bank is crucial. Several influences can cause conflict. One of them is the misunderstanding of each other 
due to misinterpretation of the sent message (e.g. unusual intonation), cultural noise that prevents correct encoding of the sent message (circumstances surrounding the individuals or caused by them-selves through gestures and mimics) and due to a lack of knowledge about communication habits of both parties. Not only oral communication tends to be misunderstood but also gestures, eye contact, smiling and mimics may lead to conflict potential. Other sources are a lack of performance, different interests or values within a team or branch. Therefore, it is important to train of how to reduce use of unnecessary words, gestures and descriptors. After becoming aware of what creates the conflict we can start to learn to get a different view on conflicts and of how to turn conflicts into something positive (Meyerson \& Martin, 1987). The application of the Iceberg Model could lead to success here.

Possible views of conflict for further research (Holger Siemons, 2017):

- Traditional view

- Interactionalist view

- Human Relations view

An unmanaged conflict will always destruct the workforce and create disharmony. It is therefore the manager's duty to collect data about his or her employees, analyze it and then pro-actively invite his or her subordinates to have an open exchange with each other to prevent that unknown/ unseen values or habits will create destructive conflict potential. Positive conflict on the other hand leads as well to synergies as also to new ideas and creative solutions, it keeps company moving forward.

J. Stewart Black and Hal Gregersen highlighted in their paper "The Right Way to Manage Expats", published in the Harvard Business Review, that in today's global economy it is not a privilege to have a workforce that is acquainted with the customs of the (globalized) world. Rather, it is a necessity for the company's own competitiveness (Black \& Gregersen, 2007). The perception of expat management is therefore of great importance, especially with regard to conflict resolution potentials and thus indirectly the increase in productivity of the individual.

Hence, on the other hand it is obligatory to train the company's local workforce to recognize and deal with potential problems during a stay abroad and negotiating with unfamiliar cultural behaviors. Relatos does not have any standardized processes to advice its employees yet.

\subsection{Treatment Instructions to Prevent Conflicts}

Interdisciplinary the concept of Corporate Governance is addressing several points that could help to improve conflict management within the Relatos headquarter. Evaluating actual behavior with these concepts could help to understand and analyze why Relatos in Frankfurt is facing tremendous problems with its foreign employees. Therefore, to support awareness and cross-cultural management the considering and applying of the following methods and theories should be presented to the upper management. 


\section{Discipline}

An important point to create a certain model function, especially for "new arrivals", is the term discipline. The South African King Report of 2016 defines discipline as the approach to top management of a company to ensure that it acts correctly and properly. This should underlie the awareness and commitment to the new circumstances within the company and help to guide foreign employees on how to cope with their new situation (Institute-ofDirectors, 2016). In this case, top management is therefore not only a professional but also a cultural point of orientation for employees.

The Relatos senior management, consisting in its majority of men above 60 years old, is tending to do work "as it has been always done". The current senior management grew up with different values and tends not to question them. As time has changed, certain behaviors and values of former times may not be acceptable and applicable anymore. This could include behaviors like to drink alcohol and smoke in the bureau, do not treat women equally, showing disrespect to cultures that differ from their own and act in an impersonalized manner.

\section{Transparency}

Another point to consider is transparency in communication, action and distribution of information. In 2002, Mallin defined that transparency in business context should make it more easily for new contractors and staff to analyze the situation or to assess and interpret the actions of their new colleagues (Mallin, 2002).

Right now, there is no standardized system of how to interact with foreign investors, e.g. from the US. This has caused several conflicts when negotiating with these investors about how to develop Relatos business abroad. Incoming employees do not have the chance to overlook processes and customs of the Frankfurt headquarter in a proper manner.

\section{Accountability}

The Institute of Directors in South-Africa responsible for the King Report IV, published in 2016, also narrowed down the issue of responsibility. Hence they defined that in order to ensure good teamwork within a company; it must be possible to trace who is and was responsible for a certain action or decision (Institute-of-Directors, 2016).

Relatos has some mechanisms to track actions made by its employees. Nevertheless, there seems to be a lack of applying these mechanisms and consequently record in an unbiased view of how projects run and how to assess success and failure. The problem of blaming foreign employees for failures they have not been responsible for because of insufficient log files has occurred several times.

\section{Fairness}

In his book Corporate Governance: Principles, Policies and Practices, Tricker (2015) emphasizes that a company must create a system that respects all the needs and interests of all those who work together, especially on specific projects and in their daily dealings with each other. It should create a balance that is conducive to the future of the company and makes the employees feel good (stress reduction, avoidance of destructive conflicts). For example, the interests of a minority shall be considered when 
applicable (food, belief etc.) (Tricker, 2015). Due to a biased habit and view of the upper management specific groups and genders are preferred sometimes, although they were not qualified by performance.

\section{Conclusion}

In the context of cross-cultural management and using the case study of the imaginary Relatos Bank, this paper has highlighted the extent to which cultural differences can lead to tension within the workforce. This can result in reduced productivity and low morale. The example of Relato was used to show that the bank is not yet able to perform the recommended changes as necessary due to a lack of the management's integrity, the missing of a concrete log file supported action management, a lack of trained and informed staff and the missing of standardized work and process schemes. It will be necessary that the manager of the certain Relatos branch releases information about the specific company or country particularities fast and in a way, which is understandable for people from different countries. Workshops may be the right tool to achieve this for outbound employees and a welcome day with instructions and important information for inbound employees. Further Relatos should redevelop how to distribute the power within the company and may consider implementing an ethic code. There are several more points to evaluate and discuss concerning cross-cultural management at Relato. Due to limitation of time and scope, this paper cannot deal with further research or analyses. However, as societies and environmental influences are fast changing and highly interesting, there is an opening for further research and deeper studies. The reader should bear in mind, that the study is based on literature and internet research only. No practical work has been done on site. Further studies could concern oneself with the impact of the different organization forms of companies, the socio-cultural influence on cross-cultural management as well as the impact of migration in Germany.

\section{Acknowledgment}

The authors would like to convey their gratitude to Prof. Dr. Imre Fertö, Prof. Dr. Gergely Tóth, Prof. Dr. Zoltán Gál and Prof. Dr. Viktória Szente for their very helpful and critical questions and comments during the preparation of this document.

\section{Authors}

Marcel Biewendt is Ph.D. Candidate at Szent István University - Kaposvár Campus, Executive Board Member and $\mathrm{COO}$ of the Institute for Digitization Aachen.

Florian Blaschke is Ph.D. Candidate at Szent István University - Kaposvár Campus and a German Project-Manager dealing with Controlling and Data-Science. 
Arno Böhnert is Ph.D. Candidate at Szent István University - Kaposvár Campus and Sales Director at Robbe \& Berking, Germany.

\section{References}

Black, J. S., \& Gregersen, H. B. (2007). The right way to manage expats. In Readings and cases in international human resource management (pp. 119-128). Routledge.

Chen, S., \& Bouvain, P. (2009). Is Corporate Responsibility Converging? A Comparison of Corporate Responsibility Reporting in the USA, UK, Australia, and Germany. Journal of Business Ethics, 87(S1), 299-317. https://doi.org/10.1007/s10551-008-9794-0

Edel, A., Kroeber, A. L., Kluckhohn, C., Untereiner, W., \& Meyer, A. G. (1954). Culture; A Critical Review of Concepts and Definitions. The Journal of Philosophy, 51(19), 559. https://doi.org/10.2307/2021459

Elizabeth Ten Dyke. (2006). 19th-Century Nationalism. Social Studies School Service. https://www.socialstudies.com/pdf/ZP304EX.pdf

Ferner, A., \& Quintanilla, J. (1998). Multinationals, national business systems and HRM: the enduring influence of national identity or a process of 'Anglo-Saxonization'. The International Journal of Human Resource Management, 9(4), 710-731. https://doi.org/10.1080/095851998340973

Fraenkel, E. (2011). Deutschland und die westlichen Demokratien (9. erweiterte Auflage). Politikwissenschaft: Vol. 3529. Nomos; UTB.

French, J. (1956). A formal theory of social power. Psychological Review, 63(3), 181-194. https://doi.org/10.1037/h0046123

Geert Hofstede. Hofstede Insights.

Hines, P. (2010). How to create and sustain a lean culture. Development and Learning in Organizations: An International Journal, 24(6). https://doi.org/10.1108/dlo.2010.08124fad.007

Hofstede, G. (2001). Culture's consequences: Comparing values, behaviors, institutions, and organizations across nations (Second edition). Sage Publications.

Holger Siemons. (2017). Cross Cultural Management. 
Institute-of-Directors. (2016). Report on Corporate Governance for South Africa: King Report IV.

https://cdn.ymaws.com/www.iodsa.co.za/resource/collection/684B68A7B768-465C-8214-E3A007F15A5A/loDSA King IV Report WebVersion.pdf

Keil, T., Maula, M., Schildt, H., \& Zahra, S. A. (2008). The effect of governance modes and relatedness of external business development activities on innovative performance. Strategic Management Journal, 29(8), 895907. https://doi.org/10.1002/smi.672

Kroeber, A. L. (1938). Basic and Secondary Patterns of Social Structure. The Journal of the Royal Anthropological Institute of Great Britain and Ireland, 68, 299. https://doi.org/10.2307/2844130

Maag, J. W. (2001). Rewarded by Punishment: Reflections on the Disuse of Positive Reinforcement in Schools. Exceptional Children, 67(2), 173-186. https://doi.org/10.1177/001440290106700203

Mallin, C. (2002). The Relationship between Corporate Governance, Transparency and Financial Disclosure. Corporate Governance, 10(4), 253255. https://doi.org/10.1111/1467-8683.00289

Meyerson, D., \& Martin, J. (1987). CULTURAL CHANGE: AN INTEGRATION OF THREE DIFFERENT VIEWS [1]. Journal of Management Studies, 24(6), 623-647. https://doi.org/10.1111/j.14676486.1987.tb00466.x

Müller-Elmau, N. (1997). Der amerikanische melting pot-Mythos als Modell nationaler Identität: Magisterarbeit. Zugl.: Mainz, Univ., Magisterarbeit, 1997. Englisch. Diplom.de Diplomarbeiten Agentur. http://www.diplom.de

Oxford-Dictionaries. (2021, April 1). Oxford Dictionaries Online. https://en.oxforddictionaries.com/definition/culture

Reisenbichler, A., \& Morgan, K. J. (2012). From "Sick Man" to "Miracle". Politics \& Society, 40(4), 549-579. https://doi.org/10.1177/0032329212461616

Schneider, S. C., Barsoux, J.-L., \& Stahl, G. K. (2014). Managing across cultures (3. ed.). 
Tricker, R. I. (2015). Corporate governance: Principles, policies and practices (Third edition). Oxford University Press.

Vandermerwe, S., \& Chadwick, M. (1989). The Internationalisation of Services. The Service Industries Journal, 9(1), 79-93.

https://doi.org/10.1080/02642068900000005

Ward, C., Bochner, S., \& Furnham, A. (2015). The psychology of culture shock (Second edition, first issued in hardback). Routledge.

Zhou, Y., Jindal-Snape, D., Topping, K., \& Todman, J. (2008). Theoretical models of culture shock and adaptation in international students in higher education. Studies in Higher Education, 33(1), 63-75.

https://doi.org/10.1080/03075070701794833 